NOTE

\title{
Selective Alkylation of Aromatic Hydrocarbons with Styrene by Solid Polymeric Oxo Acids
}

\author{
Hiroshi Hasegawa and Toshinobu Higashimura \\ Department of Polymer Chemistry, Kyoto University, \\ Yoshida, Sakyo-ku, Kyoto 606, Japan.
}

(Received January 28, 1980)

\begin{abstract}
KEY WORDS Solid Polymeric Oxo Acid / Nafion-H / Amberlyst 15 / Alkylation / Styrene / $p$-Methylstyrene / Aromatic Hydrocarbons / 1Phenyl-1-arylethane /
\end{abstract}

The Friedel-Crafts alkylation of aromatic hydrocarbons with styrene or $\alpha$-chloroethylbenzene is usually catalyzed by soluble homogeneous Brønsted or Lewis acids, yielding 1-phenyl-1-arylethane (I) (eq 1) ${ }^{1}$ Reactions with styrene commonly produce oligomers as by-products; the use of $\alpha$-chloroethylbenzene can improve the yield of $\mathbf{I},{ }^{2}$ but the starting material is not so easily available as styrene. Moreover, the removal of catalysts from products is very troublesome in these homogeneous processes. Solid acid-catalyzed heterogeneous alkylation is, therefore, desirable for the synthesis of $\mathbf{I}$, if selective and efficient.

Recently we have noticed the formation of a small amount of $\mathbf{I}\left(\mathrm{Ar}=\mathrm{C}_{6} \mathrm{H}_{5}\right)$ in the oligomerization of styrene in benzene catalyzed by solid polymeric oxo acids such as a perfluorinated resinsulfonic acid $(\text { Nafion-H })^{3}$ and poly(styrenesulfonic acid) (Amberlyst 15), ${ }^{4}$ whereas soluble oxo acids $\left(\mathrm{CF}_{3} \mathrm{SO}_{3} \mathrm{H}\right.$ and $\left.p-\mathrm{CH}_{3} \mathrm{C}_{6} \mathrm{H}_{4} \mathrm{SO}_{3} \mathrm{H}\right)$ gave only styrene dimers and low-molecular oligomers.

On the basis of these findings, the present work examines the applicability of the solid polymeric oxo acids (Nafion-H and Amberlyst 15) to the alkylation of methylbenzenes (toluene, xylenes, and trimethylbenzenes) with styrene or $p$-methylstyrene. The corresponding soluble oxo acids $\left(\mathrm{CF}_{3} \mathrm{SO}_{3} \mathrm{H}\right.$ and $\left.p-\mathrm{CH}_{3} \mathrm{C}_{6} \mathrm{H}_{4} \mathrm{SO}_{3} \mathrm{H}\right)$ and a metal halide $\left(\mathrm{BF}_{3} \mathrm{OEt}_{2}\right)$ were also used as catalysts.

\section{EXPERIMENTAL}

\section{Materials}

Commercial styrene, p-methylstyrene, and the methylbenzene substrates were washed with aqueous alkali and/or acid solutions and were distilled at least twice over calcium hydride before use. Commercial $\mathrm{BF}_{3} \mathrm{OEt}_{2}$ was purified by distillation. $\mathrm{CF}_{3} \mathrm{SO}_{3} \mathrm{H}$ (Sumitomo $3 \mathrm{M}$ Co. purity $\geqq 98 \%$ ) was used without further purification. Anhydrous $p$ $\mathrm{CH}_{3} \mathrm{C}_{6} \mathrm{H}_{4} \mathrm{SO}_{3} \mathrm{H}$ was obtained by the dehydration of its monohydrate with $\mathrm{P}_{2} \mathrm{O}_{5}$ at $120^{\circ} \mathrm{C} .{ }^{5} \mathrm{Nafion}-\mathrm{H}$ (Nafion 511 powder, 0.9 meq $\mathrm{g}^{-1}$-dry resin, du Pont $)^{3}$ and Amberlyst 15 (4.9 meq $\mathrm{g}^{-1}$-dry resin,

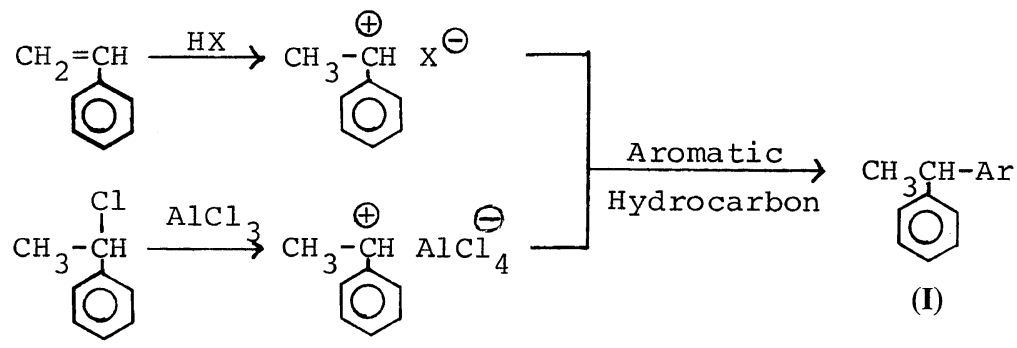


Rohm and Haas Co.), ${ }^{4}$ both in the $\mathrm{H}$-form were obtained as described elsewhere.

\section{Procedure}

The reaction was carried out under a dry nitrogen atmosphere in a flask equipped with a three-way cock and a magnetic stirrer. A weighed amount of a solid catalyst was placed in the flask and allowed to stand in contact with an aromatic substrate for an hour at $70^{\circ} \mathrm{C}$. Styrene or $p$-methylstyrene, dissolved in the substrate, was then added to initiate alkylation. The reaction with a soluble acid was initiated by the addition of a solution of this acid to a mixture of an aromatic substrate and styrene or $p$ methylstyrene maintained at $70^{\circ} \mathrm{C}$. When the styrene was completely consumed (checked by gas chromatography), methanol or 2-propanol containing a small amount of aqueous ammonia was added to stop the reaction. After removing the catalyst residue by filtration in the case of the solid catalysts or washing with water in the case of the soluble catalysts, the product was recovered by evaporation of the unreacted aromatic substrate under reduced pressure.

The yield of I was determined as follows. Since I and styrene or $p$-methylstyrene dimers (byproducts) cannot be resolved by high-performance liquid chromatography (HLC), their total yield was first measured on a HLC curve for crude product. The fraction containing $\mathbf{I}$ and the dimers was then separated by preparative HLC and analyzed by ${ }^{1} \mathrm{H}$
NMR. The content of I was determined from the relative intensity of its methyl proton singal to the methyl proton signals of styrene dimers. ${ }^{3} \mathrm{HLC}$ was run in chloroform on a JASCO-FLC-A700 chromatograph for analysis and on a JASCO-TRIROTAR chromatograph for separation with JSP-101 polystyrene gel column. NMR spectra were measured by a JOEL-MH60 spectrometer.

\section{RESULTS AND DISCUSSION}

\section{Alkylation with Styrene}

The alkylation of benzene and methylbenzenes (toluene, xylenes, and trimethylbenzenes) with styrene was carried out at $70^{\circ} \mathrm{C}$ at a low concentration $(0.10 \mathrm{M})$ of styrene to prevent its oligomerization. After the styrene was completely consumed, the products were mainly I and the styrene dimers (1,3diphenyl-1-butene and 1-methyl-3-phenylindan), with the remainder being a small amount of oligostyrenes and polyalkylated aromatics. The yields of I and the styrene dimers are summarized in Table $\mathrm{I}$, along with the structure of $\mathrm{I}$ determined by ${ }^{1} \mathrm{H}$ NMR.

The adduct obtained from toluene consisted of $95 \% p$ - and $5 \% o$-isomers. The other aromatics were alkylated with a nearly $100 \%$ regioselectivity according to NMR measurement; no isomerization of the starting materials was observed.

The Nafion-H catalyzed alkylation gave very high yields of $\mathbf{I}$ without contamination by styrene dimers

Table I. Alkylation of methylbenzenes with stryrene by acid catalysts at $70^{\circ} \mathrm{C}^{\mathrm{a}, \mathrm{b}}$

\begin{tabular}{|c|c|c|c|c|c|}
\hline \multirow{2}{*}{$\begin{array}{l}\text { Aromatic } \\
\text { substrate }\end{array}$} & \multicolumn{5}{|c|}{$\%$ Yield of $\mathbf{I}(\%$ Yield of styrene dimers $)$} \\
\hline & Nafion-H & Amberlyst 15 & $\mathrm{CF}_{3} \mathrm{SO}_{3} \mathrm{H}$ & $p-\mathrm{CH}_{3} \mathrm{C}_{6} \mathrm{H}_{4} \mathrm{SO}_{3} \mathrm{H}$ & $\mathrm{BF}_{3} \mathrm{OEt}_{2}$ \\
\hline Benzene & $13.7(33.2)$ & $10.7(25.7)$ & $0 \quad(75.0)$ & $0 \quad(84.3)$ & $0 \quad(22.3)$ \\
\hline Toluene $e^{c}$ & $86.2(0)$ & $61.5(0)$ & $53.6(33.5)$ & $51.5(38.2)$ & $19.5(5.0)$ \\
\hline$p$-Xylene & $67.3(0)$ & $56.0(0)$ & $47.4(35.1)$ & $-\quad-$ & $29.9(7.1)$ \\
\hline$o$-Xylene ${ }^{\mathrm{c}}$ & $95.0(0)$ & $83.0(0)$ & $83.3(0)$ & $-\quad-$ & $71.9(0)$ \\
\hline$m$-Xylene $e^{c}$ & $93.0(0)$ & $86.3(0)$ & $91.7(0)$ & $95.0(0)$ & $70.0(0)$ \\
\hline $\begin{array}{l}\text { 1,2,4-Trimethyl- } \\
\text { benzene }^{c}\end{array}$ & $97.3(0)$ & $95.0(0)$ & $94.6(0)$ & - & $83.8(0)$ \\
\hline $\begin{array}{l}\text { 1,3,5-Trimethyl- } \\
\text { benzene }\end{array}$ & $95.6(0)$ & - & - & - & - \\
\hline
\end{tabular}

${ }^{\mathrm{a}}[\text { Styrene }]_{0}=0.10 \mathrm{M}$; reaction time, $1 \mathrm{~h}$; conversion of styrene $=100 \%$.

b $[\text { Catalyst }]_{0}=$ Nafion- $\mathrm{H}, 3.0 \mathrm{mM}\left(3.3 \mathrm{mg} \mathrm{cm}^{-3}\right)$; Amberlyst $15,10 \mathrm{mM}\left(2.0 \mathrm{mg} \mathrm{cm}{ }^{-3}\right) ; \mathrm{CF}_{3} \mathrm{SO}_{3} \mathrm{H}, 0.30 \mathrm{mM} ; p$ $\mathrm{CH}_{3} \mathrm{C}_{6} \mathrm{H}_{4} \mathrm{SO}_{3} \mathrm{H}, 30 \mathrm{mM} ; \mathrm{BF}_{3} \mathrm{OEt}_{2}, 80 \mathrm{mM}$ (with $40 \mathrm{mM}$ of added water as cocatalyst).

c Alkylation sites: toluene, 4-C (95\%) and 2-C (5\%); $o$-xylene, 4-C; $m$-xylene, 4-C; 1,2,4-trimethylbenzene, 5-C. 
for most of the aromatics employed. Nearly specific and quantitative monoalkylation took place with $o$ and $m$-xylene and the trimethylbenzenes. The data in Table I clearly demonstrate that Nafion-H is superior to the other catalysts in the liquid-phase, as well as in the gas-phase, ${ }^{6}$ Friedel-Crafts alkylation.

The alkylation selectivity depended greatly on the catalysts, especially in the reactions of less activated aromatics (benzene, toluene, and $p$-xylene). For instance, the yield of $I$ from toluene decreased in the order Nafion- $\mathrm{H}>$ Amberlyst $15>\mathrm{CF}_{3} \mathrm{SO}_{3} \mathrm{H} \sim p$ $\mathrm{CH}_{3} \mathrm{C}_{6} \mathrm{H}_{4} \mathrm{SO}_{3} \mathrm{H} \gg \mathrm{BF}_{3} \mathrm{OEt}_{2}$. This order shows that the solid polymeric oxo acids are more effective as alkylation catalysts than the corresponding soluble oxo acids.

The higher yield of $\mathbf{I}$ for the oxo acids, either heterogeneous or homogeneous, than for $\mathrm{BF}_{3} \mathrm{OEt}_{2}$ (a metal halide) is due to the nucleophilic oxo-acid anions that can suppress the addition of styrene to the cationic intermediate, as shown in the selective dimerization of styrene. ${ }^{7}$

The yield of I increased, as expected, with an increase in the number of methyl groups attached to the aromatic hydrocarbons.

\section{Alkylation with p-Methylstyrene}

The results of the alkylation with $p$-methylstyrene are listed in Table II. The yield of alkylation products (II) with $p$-methylstyrene is lower than that of I with styrene because of the higher cationic polymerizability of $p$-methylstyrene. However, the superiority of Nafion-H over $\mathrm{CF}_{3} \mathrm{SO}_{3} \mathrm{H}$ as alkylation catalyst is clearly shown in Table II.
Table II. Alkylation of toluene and $m$-xylene with $p$-methylstyrene $\left(p\right.$-MeSt) at $70^{\circ} \mathrm{C}^{\mathrm{a}, \mathrm{b}}$

\begin{tabular}{|c|c|c|}
\hline \multirow{2}{*}{$\begin{array}{l}\text { Aromatic } \\
\text { substrate }\end{array}$} & \multicolumn{2}{|c|}{$\begin{array}{c}\% \text { Yield of } \mathbf{I I} \\
(\% \text { Yield of } p \text {-MeSt dimers })\end{array}$} \\
\hline & Nafion-H & $\mathrm{CF}_{3} \mathrm{SO}_{3} \mathrm{H}$ \\
\hline Toluene $^{c}$ & $25.1(15.3)$ & $9.5(11.3)$ \\
\hline$m$-Xylene ${ }^{\mathrm{c}}$ & $49.4(0)$ & $29.2(0)$ \\
\hline
\end{tabular}

${ }^{\mathrm{a}}[p-\mathrm{MeSt}]_{0}=0.10 \mathrm{M}$; reaction time, $1 \mathrm{~h}$; conversion of $p$ $\mathrm{MeSt}=100 \%$

b [Catalyst $]_{0}:$ Nafion-H, $3.0 \mathrm{mM} \quad\left(3.3 \mathrm{mg} \mathrm{cm}^{-3}\right)$; $\mathrm{CF}_{3} \mathrm{SO}_{3} \mathrm{~h}, 0.30 \mathrm{mM}$.

c Alkylation sites: toluene, 4-C (95\%), 2-C (5\%) mXylene, 4-C

\section{REFERENCES}

1. For a review, G. A. Olah, Ed., "Friedel-Crafts and Related Reactions," Vol. II, John Wiley \& Sons Inc., New York, N.Y., 1964, p 57.

2. P. Finocchiaro, Tetrahedron, 27, 581 (1971).

3. H. Hasegawa and T. Higashimura, Polym. J., 11, 737 (1979).

4. H. Hasegawa and T. Higashimura, J. Polym. Sci. Polym. Chem. Ed., in press.

5. L. F. Fieser, "Experiments in Organic Chemistry," 3rd ed, D. C. Heath and Co. Boston, 1955, p 144.

6. G. A. Olah, J. Kaspi, and J. Bakala, J. Org. Chem., 42, 4187 (1977) and succeeding papers.

7. T. Higashimura, M. Hiza, and H. Hasegawa, Macromolecules, 12, 217 (1979). 